\title{
Design of a Parabolic Trough Solar Collector Using a Concentrator with High Reflectivity
}

\author{
Ahmet Çăglar \\ Akdeniz University, Faculty of Engineering, Department of Mechanical Engineering \\ Dumlupınar Boulevard, Engineering Faculty, B-309, Campus, Antalya, 07058, Turkey \\ acaglar@akdeniz.edu.tr
}

\begin{abstract}
Parabolic trough collectors are used for industrial applications in a temperature range $150-400{ }^{\circ} \mathrm{C}$. Flat-plate collectors are not appropriate for these high temperatures. In concentrating solar power technology, the optical efficiency of solar collector influences collector performance significantly. In this paper, two different reflective surfaces are used to increase the optical efficiency of a parabolic trough solar collector. 316-L chrome plate and aluminium composite panel are used for the reflective surface. The results from two surfaces are compared with each other. A glass cover for the absorber is used and the results from absorber tube with and without glass cover are also compared.
\end{abstract}

Keywords: Concentrating power, Parabolic trough, Optical efficiency, Reflectivity

\section{Introduction}

The optimum concentrating solar power (CSP) system design combines a relatively large, efficient optical surface, harvesting the incoming solar irradiation and concentrating it onto a solar receiver with a small aperture area. The solar receiver is a high-absorptance and transmittance, low-reflectance, radiative/convective heat exchanger that emulates as closely as possible the performance of a radiative black body [1]. On the other hand, the concentrator must have a high reflectivity and a high surface accuracy to obtain an efficient solar collector optically. The solar thermal element can be a parabolic trough field, a linear Fresnel reflector field, a central receiver system or a field of parabolic dishes, commonly designed for a normal incident radiation of $800-900 \mathrm{~W} / \mathrm{m}^{2}[1]$.

The parabolic trough collectors (PTC) consist of solar collectors (mirrors), heat receivers and support structures. The parabolic-shaped mirrors are constructed by forming a sheet of reflective material into a parabolic shape that concentrates incoming sunlight onto a central receiver tube at the focal line of the collector. The receiver comprises the absorber tube (usually metal) inside an evacuated glass envelope. The absorber tube is generally a coated stainless steel tube, with a spectrally selective coating that absorbs the solar (short wave) irradiation well, but emits very little infrared (long wave) radiation. This helps to reduce heat loss. Evacuated glass tubes are used because they help to reduce heat losses. A heat transfer fluid (HTF) is circulated through the absorber tubes to collect the solar energy and transfer it to the steam generator or to the heat storage system. Most existing parabolic troughs use synthetic oils as the heat transfer fluid, which are stable up to $400^{\circ} \mathrm{C}$. Parabolic troughs are the CSP technology with the most commercial operating experience [2].

In literature, researches on PTCs focus especially on reflective surface, absorber/receiver design and hence the increase of the efficiency and usage area of the collector. Khatri [3] attached optical fibers at the exit aperture of the concentrator where the energy is focused by its surfaces in order to receive and transport the concentrated flux. The fibers transport the concentrated energy to the flux receiving device which consists of two concentric cylinders. Heat losses by radiation and convection is presented to cause a decrease in the optical efficiency and hence the collector performance by Rabl [4]. Canavarro et al. [5] has proposed a new compound elliptical-type concentrator for a parabolic primary with a tubular receiver to obtain higher concentration values, a possible starting point for higher conversion efficiency.

This paper presents a comparison between the fluid outlet temperature and efficiency of the system for two concentrators made of different material; one is made of chrome plate and the other one is made of composite aluminium panel. Another comparison is made between the absorber tube with and without glass cover in terms of fluid temperature and efficiency. 


\section{Experimental Study}

The experimental setup for the parabolic trough solar collector is consist of supporting structure, concentrator (reflective surface), absorber tube located at the focal point and storage tank. A view from the experimental setup is shown in Figure 1. Aluminium composite plate was mounted on the supporting structure of the concentrator by bending method. The stainless chrome plate is covered on the composite plate by bolting from suitable points without any bending process. Thus a high accurate surface was obtained without causing any reflection loss.

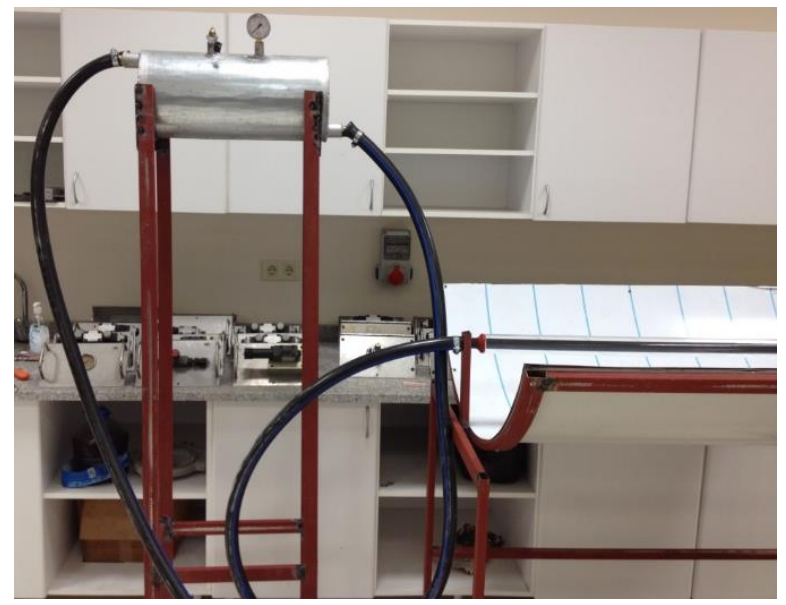

Fig. 1: A view from the experimental setup.

The dimensions and focal point of the concentrator can be shown in Figure 2. The focal point is calculated by the following expression:

$$
\mathrm{y}=\frac{X^{2}}{4 f}
$$

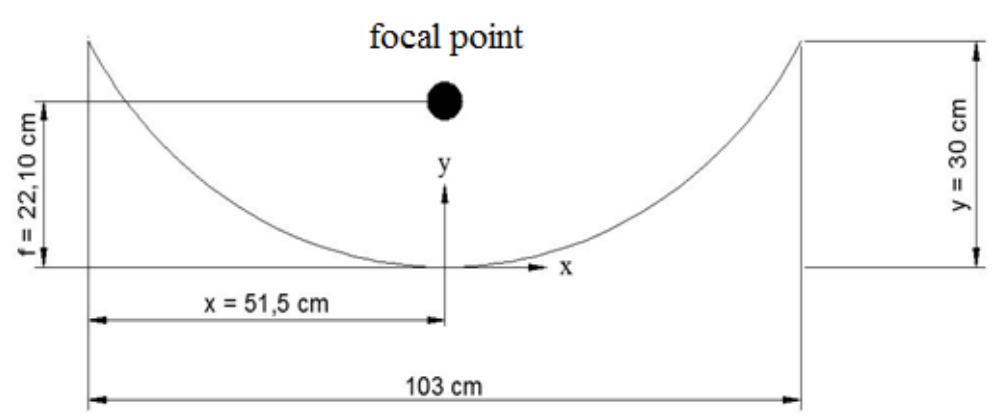

Fig. 2: Concentrator dimensions and focal point.

For the absorber, copper tube with $28 \mathrm{~mm}$ diameter and $1 \mathrm{~m}$ wall thickness was painted using black lusterless paint whereafter was firstly painted by static electrolytic galvanizing and ovendried at $400{ }^{\circ} \mathrm{C}$. The absorber tube was covered by a glass tube with $50 \mathrm{~mm}$ diameter and $2.3 \mathrm{~mm}$ wall thickness. The storage tank was made of stainless steel. Its capacity is 20 litres.

\section{Results and Discussion}

Experiments were performed in Antalya, Turkey, in May 2015, at clear weather conditions. Temperature variation of the fluid inside the storage tank was measured. Temperature measurements were recorded with 15-minute time periods. Two cases have been investigated: in the first case, the reflector made of 316-L chrome plate was tested for an absorber tube with a glass cover and was compared with the test results for a bare absorber tube without any 
cover; in the second case, the results for the concentrator with 316-L chrome plate are compared with that for the concentrator with composite aluminium panel.

Figure 3 shows the variation of fluid temperature inside the storage tank with time for the 316-L type chrome plate reflector and the absorber with the glass cover. Figure 4 shows the variation of fluid temperature with time for the 316-L type chrome plate reflector and the bare absorber (without a glass cover). Figure 5 shows the variation of fluid temperature with time for the composite aluminium reflector and the bare absorber.

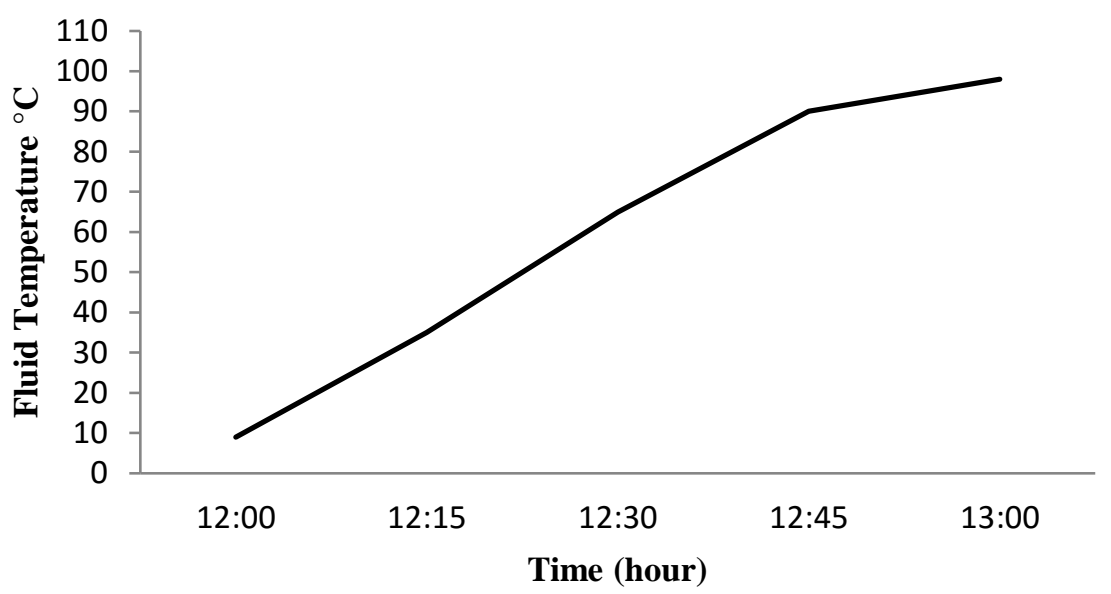

Fig. 3: Variation of fluid temperature inside the storage tank with time for the 316-L type chrome plate reflector and the absorber with glass cover.

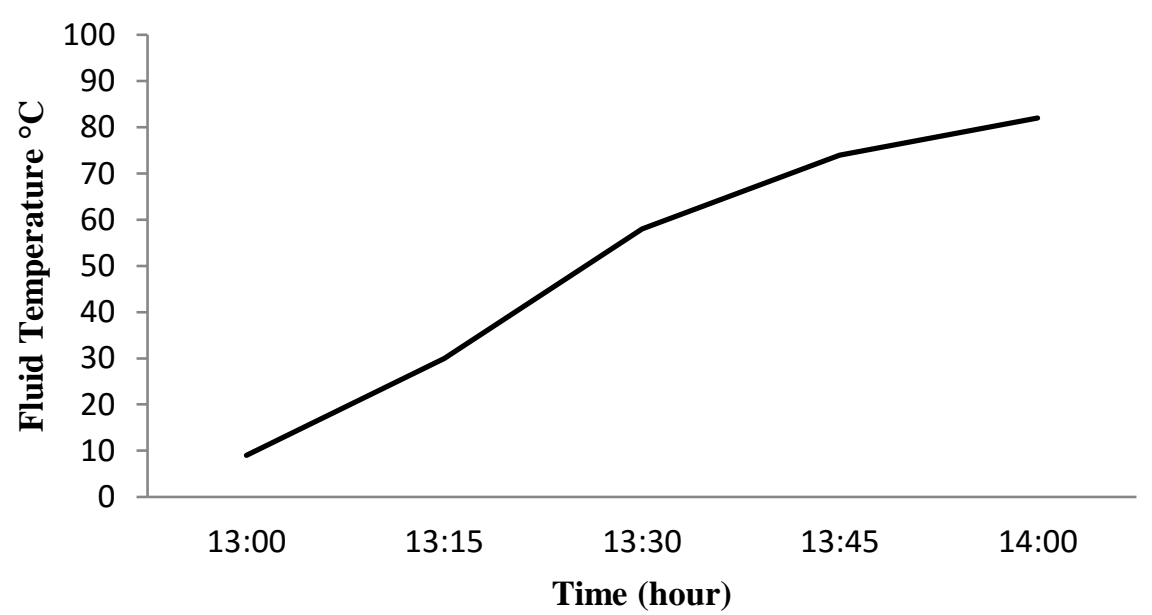

Fig. 4: Variation of fluid temperature inside the storage tank with time for the 316-L type chrome plate reflector and the absorber without glass cover.

Results shows that in the first comparison, i.e. the comparison between the fluid temperatures for the chrome plate reflector and absorber tube with and without glass cover seen in Fig.s 3 and 4, the fluid temperature reaches $98{ }^{\circ} \mathrm{C}$ in the case of absorber tube with glass cover while it reaches $82{ }^{\circ} \mathrm{C}$ for the absorber tube without glass cover. It is therefore proven that a glass cover reduces the heat losses yielding better fluid temperatures and better collector performances.

In the second comparison, i.e. the comparison between the fluid temperatures for the chrome plate reflector and composite aluminium panel reflector seen in Fig.s 4 and 5, the fluid temperature reaches $87^{\circ} \mathrm{C}$ for the composite aluminium panel reflector while it reaches $82{ }^{\circ} \mathrm{C}$ for the chrome plate reflector. In this case, the absorber is not covered by the glass. Results show that the PTC with aluminium composite panel reflector has a better performance than the chrome plate reflector due to the higher reflectivity value of the composite aluminium plate $(\approx 0.89)$. 


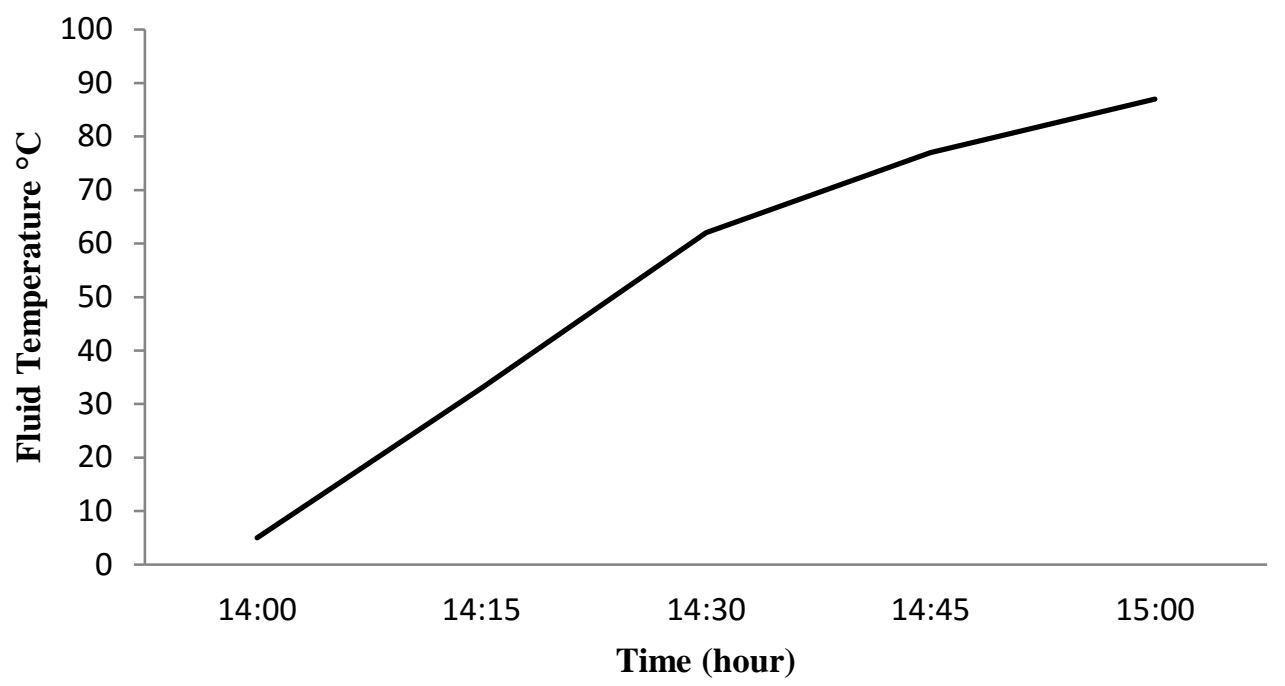

Fig. 5: Variation of fluid temperature with time for the composite aluminium reflector and the bare absorber.

Solar radiation values measured during the experiments is shown in Table 1. Although the solar radiation influences the temperature of the fluid and the performance of the collector, this effect can be neglected for the present study since the solar irradiation did not change significantly for the three different cases.

Table 1: Solar radiation measurements.

\begin{tabular}{|c|c|}
\hline Time & Solar irradiation, $I_{b}\left(\mathrm{~W} / \mathrm{m}^{2}\right)$ \\
\hline $12: 00-13: 00$ & 931,92 \\
\hline $13: 00-14: 00$ & 937,98 \\
\hline $14: 00-15: 00$ & 925,05 \\
\hline
\end{tabular}

The collector efficiency is also compared for the three cases. The efficiency of the collector can be calculated by the following expression:

$$
\eta=\frac{\dot{m} c_{p} \Delta T}{I_{b} A_{c}}
$$

where $\dot{m}$ is mass flow rate $(\mathrm{kg} / \mathrm{s}), c_{p}$ is specific heat of the fluid $(\mathrm{kJ} / \mathrm{kg} . \mathrm{K}), \Delta T$ is temperature difference $(\mathrm{K}), A_{c}$ is collector aperture area $\left(\mathrm{m}^{2}\right)$ and $I_{b}$ is solar beam radiation $\left(\mathrm{W} / \mathrm{m}^{2}\right)$.

The efficiencies calculated for three cases are represented in Figure 6. The efficiency of the collector for the chrome plate reflector with a glass cover, the chrome plate reflector without a glass cover and the composite aluminium panel reflector without a glass cover is $0.92,0.73$ and 0.82 , respectively. The results show that the composite aluminium panel yields a better performance due to its higher reflectance coefficient. It can be also concluded that glass cover has a significant effect on the thermal performance of the PTC.

\section{Conclusion}

In this paper, two different reflective surfaces are experienced to increase the efficiency of a PTC. 316-L chrome plate and aluminium composite panel are used for the reflective surface. The results from two surfaces are compared with each other. Another comparison is performed between the absorber tube with and without glass cover. Results show that the composite aluminium panel reflector presents a better performance than the chrome plate reflector due to its higher reflectivity. Results also show that the absorber/receiver tube with a glass cover has less losses and presents a betters performance. 


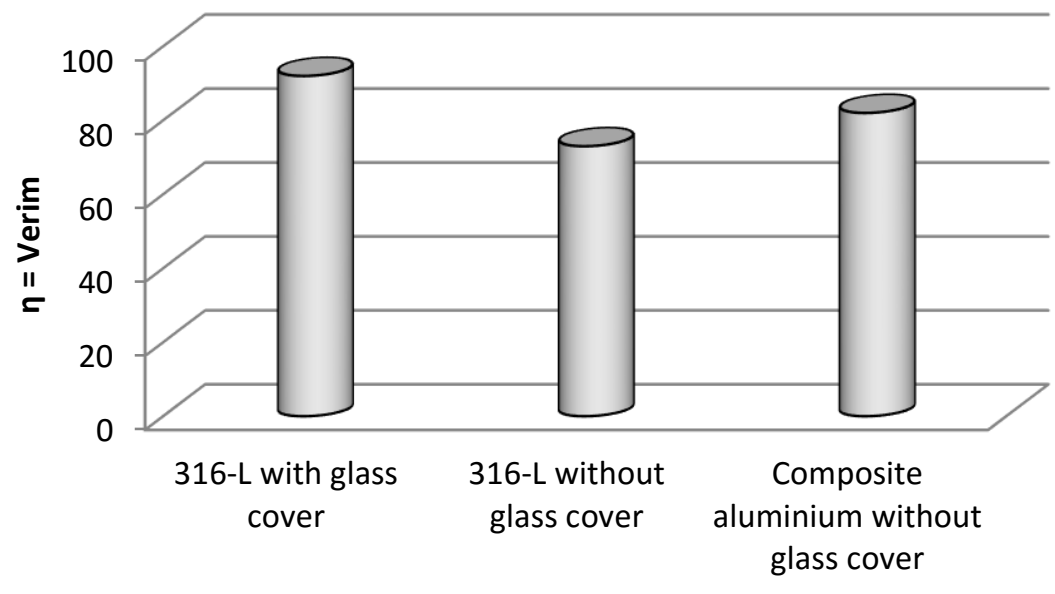

Fig. 6: Collector efficiency.

\section{References}

[1] M. Romero-Alvarez and E. Zarza, "Concentrating Solar Thermal Power," in Handbook of Energy Efficiency and Renewable Energy, F. Kreith, D. Y. Goswami, CRC Press, Taylor and Francis Group, LLC, 2007.

[2] IRENA, "Concentrating Solar Power," in Renewable Energy Technologies: Cost Analysis Series, vol. 1, IRENA, 2012.

[3] N. M. Khatri, "A solar energy collection system utilizing optical fibers and compound parabolic concentrators," Ph.D. Thesis, University of Cincinnati, USA, 1991.

[4] A. Rabl, "Optical and thermal properties of compound parabolic concentrators," Solar Energy, vol. 18, no. 6, pp. 497$511,1976$.

[5] D. Canavarro, J. Chaves, and M. C. Pereira, "A novel Compound Elliptical-type Concentrator for parabolic primaries with tubular receiver,” Solar Energy, vol. 134, pp. 383-391, 2016. 